Article

\title{
Formation of Tribofilm in the Friction of Fluorinated Diamond-Like Carbon (FDLC) Film against Ti6A14V in Bovine Serum Albumin (BSA) Solution
}

\author{
Tengfei Zhang ${ }^{1,2}$, Zhaoying Xu ${ }^{1}$, Yongyao Su ${ }^{1}$, Jinbiao Wang ${ }^{1}, \mathrm{Lu} \mathrm{Li}^{1, *}$, Kok Boon Chong ${ }^{1,3}$, \\ Xiaodong Hou ${ }^{2}$ and Sanjooram Paddea ${ }^{2}$ \\ 1 Chongqing Key Laboratory of Materials Surface \& Interface Science, Chongqing University of Arts and \\ Sciences, Chongqing 402160, China; tengfeizhang@126.com (T.Z.); xzhydchn@163.com (Z.X.); \\ yongyaosu@126.com (Y.S.); wlsf108@163.com (J.W.); kokboonc@sunway.edu.my (K.B.C.) \\ 2 Centre of Excellence for Advanced Materials, Dongguan 523808, China; xiaodong.hou@ceamat.com (X.H.); \\ Sanjooram.Paddea@ceamat.com (S.P.) \\ 3 Jeffrey Sachs Center on Sustainable Development, Sunway University, Bandar Sunway 47500, Malaysia \\ * Correspondence: lli@cqwu.edu.cn; Tel.: +86-02349512175
}

Received: 24 August 2020; Accepted: 18 September 2020; Published: 20 September 2020

\begin{abstract}
A route to reducing the wear of the metal counterpart in the friction of meatal against diamond-like carbon (DLC) is to form a lubricating tribofilm on the metal counterface. However, in liquid lubricating conditions, the formation of tribofilm can be influenced by both the lubricating medium and the counterpart material. Here we report the effect of lubricating biomolecule and doping fluorine element on the formation of tribofilm in fluorinated DLC (FDLC)-Ti6Al4V friction system. A group of ball-on-disc frictional experiments with different sliding speeds and normal loads were performed in phosphate buffer solution (PBS) and bovine serum albumin (BSA) solution. The results showed the formation of tribofilm was inhibited by the absorption of biomolecules on the frictional surface, thus improving the friction coefficient and wear of Ti6Al4V counterpart. Doping fluorine into DLC film also can restrain the formation of tribofilm on Ti6Al4V counterface. As a result, tribofilm is difficult to form when Ti6Al4V counterface slides against FDLC in BSA solution. Fluorinated DLC film should be considered carefully for the anti-wear use in body fluid containing biomolecules because it might cause severe wear of the counterpart material.
\end{abstract}

Keywords: tribofilm; fluorinated diamond-like carbon; body fluid; friction; wear

\section{Introduction}

Tribofilm is a thin solid film generated as a result of sliding contact, which is adhered on the worn surface working as a "third body" with remarkable influence on both the friction behavior and the wear performance. Tribofilm may come from lubricating medium. In Liao's study, a graphitic tribofilm formed on the surface of an explanted $\mathrm{CrCrMo}$ artificial hip joint, which was generated from biomolecules in the lubricating body fluid and played a role in reducing wear and corrosion [1]. Erdemir also reported a carbon-based tribofilm formed on MoN counterface through the dehydrogenation of linear olefins in the lubricating oil [2]. Some particular counter material can generate tribofilm itself, which is called self-lubricating material, such as diamond-like carbon (DLC) film. DLC film is widely used in the engine industry, as well as for spacecraft and medical devices. The tribofilm generated from DLC film, which is usually called transfer film, normally has a graphite like structure and acts as a solid lubricant to reduce friction and wear [3]. Using the self-lubricating DLC film in a lubricating medium is a promising way to minimize the wear. However, the interaction between DLC film and 
lubricating medium is complicated, the formation mechanism and function of tribofilm has not been fully understood.

In our previous study, the composition of the tribofilm generated from DLC film was influenced by the lubricating water. It seemed that water could inhibit the formation of brittle metal oxides in the tribofilm, thus improving the lubrication effect [4]. Lafon-Placette investigated the tribological behavior of DLC film in base oil, the results showed that the counterpart nature played a significant role on the wear of tetrahedral amorphous carbon (ta-C) and suggested that elements with a carbophilic character could promote the formation of a heterogeneous carbon-containing tribofilm on the steel surface [5]. Except for the lubricating medium and counterface material, sliding speed, normal load, etc. also has influence on the formation of tribofilm. Akihiro Tanaka suggested transfer film was easier to form on SiC counterfaces at low speed and low load rather than at high speed and high load [6]. The above studies show that the formation of tribofilm is influenced by many factors and it must be discussed separately in different tribo-systerms.

When the DLC film is used in medical devices, body fluids act as lubricating media, which contain water, inorganic salts, biomolecules and so on. It has been proved that water can act as lubricant and lower the friction coefficient [7]. In M. Suzuki's study, water was reported to promote the formation of transfer film [8]. Inorganic salt ions can not only absorb on the friction surface, but penetrate into the film-substrate interface, which influences both friction and corrosion $[9,10]$. Biomolecules also can absorb on the friction surface and play an important role in the friction and wear behavior of DLC film in simulated body fluid [11,12]. Hang reported that biomolecules could increase the friction, but reduce the wear for DLC surfaces [13]. Guo investigated the tribological behavior of DLC film in simulated body fluid; it was found that biomolecules could absorb on the surface of DLC and inhibit the formation of tribofilm [14].

Fluorinated DLC film has been investigated for medical use due to its low surface energy, good blood compatibility and biocompatibility [15]. However, the tribological properties of fluorinated DLC films in physiological environments have not been fully explored. In this paper, fluorinated DLC film and undoped DLC film were prepared on Ti6Al4V substrates. The trbiological property of the DLC films was studied in phosphate buffer solution (PBS) and bovine serum albumin (BSA) solution. The effect of BSA on the formation and function of tribofilm from fluorinated DLC film was discussed.

\section{Experiment}

\subsection{Film Preparation}

Fluorinated DLC film and undoped DLC film were prepared on flat Ti6Al4V substrates by hollow cathode plasma immersion ion implantation (HCPIII) method. The substrates were ground and polished to a roughness of $2-10 \mathrm{~nm}$ and then ultrasonically cleaned in acetone and alcohol, respectively. Before deposition, the substrates were sputter cleaned in Ar plasma under a pulsed voltage $(-800 \mathrm{~V}$, $1500 \mathrm{~Hz}, 30 \%$ ) for $30 \mathrm{~min}$ to remove contaminants and oxide layers. A thin Si-containing layer was prepared between DLC film and substrate using $\mathrm{SiH}_{4}$ plasma at a bias voltage $(-1800 \mathrm{~V}, 1500 \mathrm{~Hz}$, $30 \%$ ) for $15 \mathrm{~min}$ to promote the adhesion. Fluorinated hydrogenated DLC films (FDLC) and undoped hydrogenated DLC films (DLC) were deposited under a pulsed voltage ( $-900 \mathrm{~V}, 1500 \mathrm{~Hz}, 30 \%)$ to a thickness of about $1.6 \mu \mathrm{m}$ and $1.7 \mu \mathrm{m}$ using $\mathrm{C}_{2} \mathrm{H}_{2}+\mathrm{CF}_{4}$ plasma and $\mathrm{C}_{2} \mathrm{H}_{2}$ plasma, respectively. The effective bias current is in the range of 0.5 to $0.9 \mathrm{~A}$. The content of fluorine in FDLC is about $3.2 \%$, as determined by X-ray photoelectron spectroscopy (XPS, PHI-5700, ULVCA, Chanhassen, US) with unmonochromatized $\mathrm{Mg} \mathrm{K} \alpha$ radiation $(\mathrm{h} v=1253.6 \mathrm{eV})$.

\subsection{Friction and Wear}

The friction and wear properties of DLC films were evaluated on a ball-on-disc reciprocating tribometer (CSEM, Neuchâtel, Switzerland). Ti6Al4V balls $(\Phi 6 \mathrm{~mm})$ were used as counterfaces. The applied loads were $0.5 \mathrm{~N}, 1 \mathrm{~N}$ and $2 \mathrm{~N}$, the sliding speeds were $2 \mathrm{~cm} / \mathrm{s}, 3 \mathrm{~cm} / \mathrm{s}$ and $4 \mathrm{~cm} / \mathrm{s}$. PBS $(\mathrm{NaCl}$ : 
$\left.8 \mathrm{~g} / \mathrm{L}, \mathrm{KCl}: 0.2 \mathrm{~g} / \mathrm{L}, \mathrm{Na}_{2} \mathrm{HPO}_{4}: 1.44 \mathrm{~g} / \mathrm{L}, \mathrm{KH}_{2} \mathrm{PO}_{4}: 0.24 \mathrm{~g} / \mathrm{L}\right)$ and BSA solution $(10 \mathrm{~g} / \mathrm{L}$ BSA dissolved in PBS) were used as the lubricating media. The length of wear track was $5 \mathrm{~mm}$ and the number of reciprocation cycles was 500. After the friction test, the wear scars on Ti6Al4V balls were observed by an optical microscope (OM, Axio Lab.A1, ZEISS, Thüringen Jena, Germany). The structure of the transfer films on the Ti6Al4V balls were detected by Raman spectroscopy (inVia-reflex, Renishaw, New Mills, UK). The laser wavelength of the Raman measurements was $532 \mathrm{~nm}$. The wear loss of the Ti6Al4V balls was estimated by the following Equation (1) [16]:

$$
\mathrm{V}=\frac{\pi \mathrm{b}^{4}}{64 \mathrm{R}} \text { for } \mathrm{b}<<\mathrm{R},
$$

where $\mathrm{V}, \mathrm{b}$ and $\mathrm{R}$ are the material loss, diameter of the wear scar and diameter of the Ti6Al4V ball, respectively.

\section{Results}

\subsection{Friction}

The friction coefficients of DLC films sliding against Ti6Al4V balls in BSA and PBS were shown in Figure 1. When Ti6Al4V slides against DLC in BSA (Figure 1a), the friction coefficients decreased with the increase in sliding speed and normal load, which was consistent with the results in Kim's study [17]. When the friction was conducted in PBS (Figure 1b), without the influence of biomolecules, the friction coefficient (Figure 1b) are lower than those in BSA (Figure 1a). The results correspond with Wu's study [18]. Compared to the friction coefficients in BSA solution, the friction coefficients in PBS varied slightly under different test conditions. It seemed the friction was less affected by the sliding speed and the normal load in PBS. When Ti6Al4V slides against FDLC, the same tendency can be seen from Figure 1c,d, the friction coefficients are higher and more discrete in BSA than in PBS. FDLC shows higher friction coefficient than DLC in BSA solution, especially under low load and low speed, probably because low fluorine doping DLC can absorb more biomolecules than DLC [19].

\subsection{Wear of Ti6Al4V Counterfaces}

\subsubsection{Morphology of the Counterfaces}

The OM images of the Ti6Al4V counterfaces are shown in Figure 2. It can be seen that when Ti6Al4V balls slid against DLC samples in BSA solutions, clear wear scars were generated on the worn surfaces with only little debris adhering along the grooves (Figure 2a). However, in PBS, all the wear scars are covered with tribofilms (Figure 2b). It seems that the biomolecules in BSA solutions are harmful to the formation of transfer film. When Ti6Al4V balls slide against FDLC samples, the same phenomenon can be seen. Transfer films formed along the sliding direction in PBS (Figure 2d), while no continuous transfer film could be observed after the friction experiment in BSA solution (Figure 2c). Compared with the transfer films formed from DLC (Figure 2b), the ones from FDLC (Figure 2d) cover less area of the wear scars. 

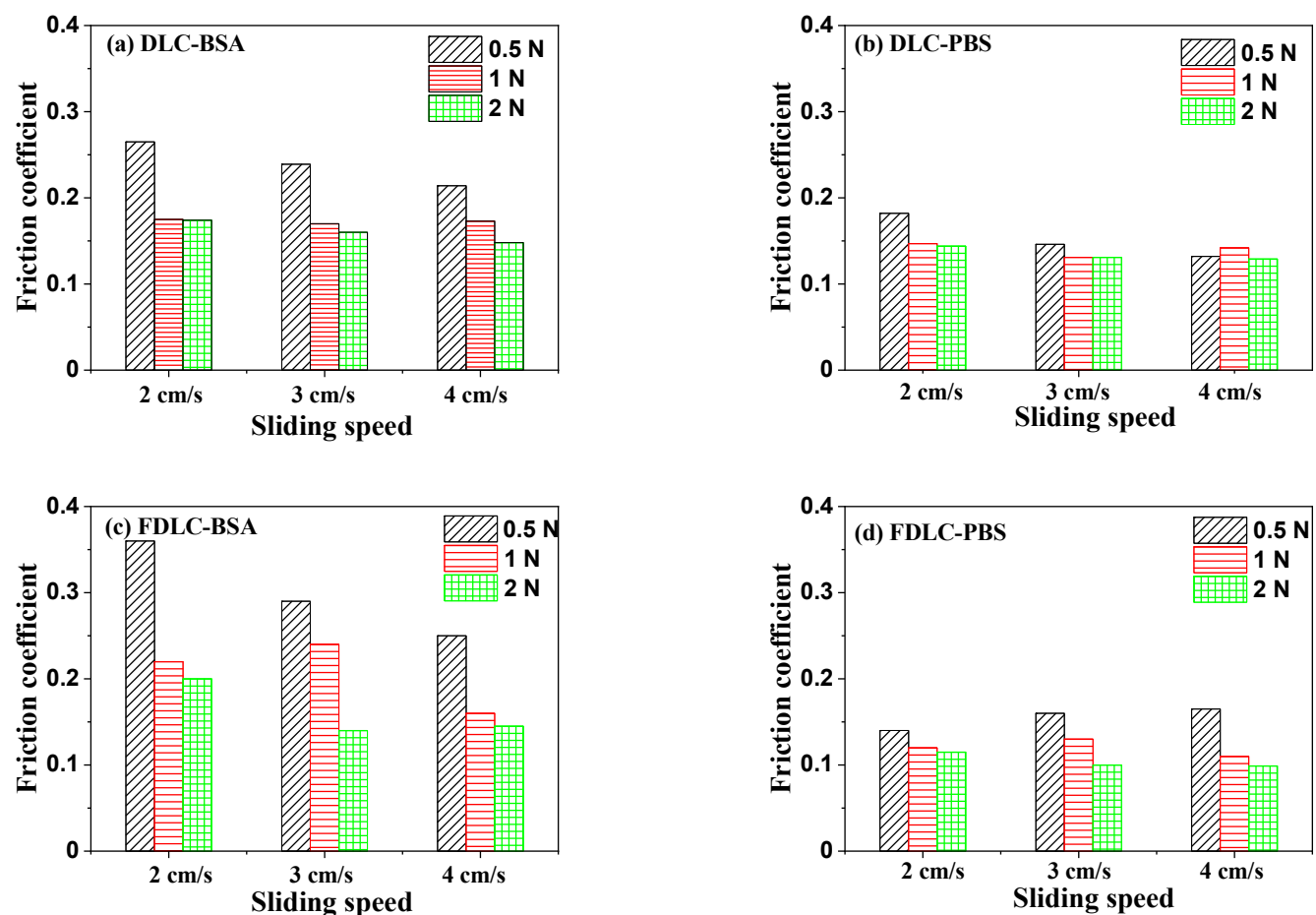

Figure 1. Friction coefficients of Ti6Al4V balls sliding against (a) DLC films in BSA solution, (b) DLC films in PBS, (c) FDLC films in BSA solution and (d) FDLC films in PBS under different normal loads and sliding speeds.
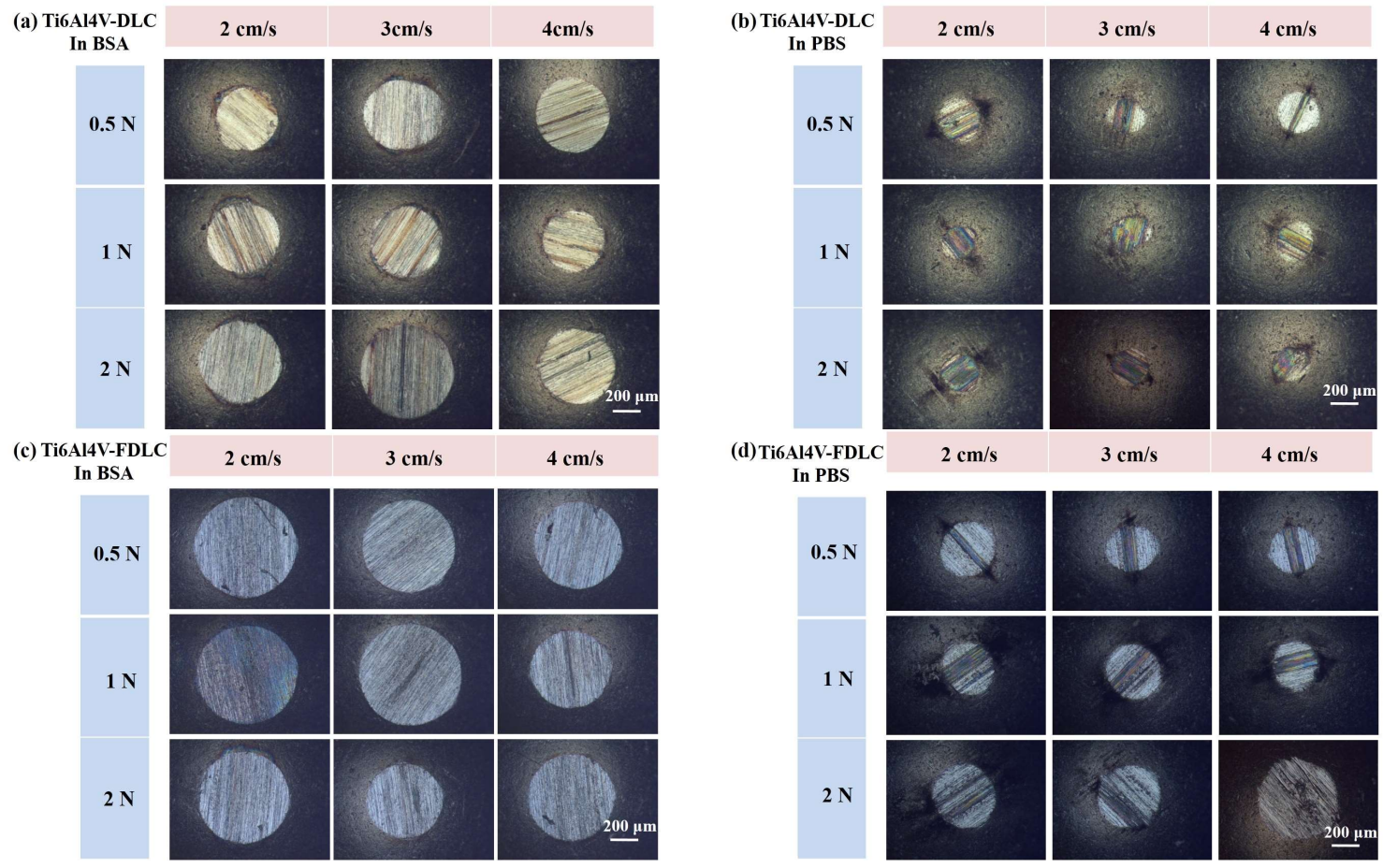

Figure 2. Optical microscope images of the wear scars onTi6Al4V balls generated by (a) DLC films in BSA solution, (b) DLC films in PBS, (c) FDLC films in BSA solution and (d) FDLC films in PBS under different normal loads and sliding speeds.

\subsubsection{Structure of Tribofilms}

The amplifying images of the wear scars under $1 \mathrm{~N}, 2 \mathrm{~cm} / \mathrm{s}$ conditions were shown in Figure 3. From Figure $3 b$, it can be seen the transfer film formed against DLC in PBS covers almost all the area of 
wear scar, while the transfer film formed against FDLC in PBS (Figure 3d) only covers the middle of the wear scar. It seems the transfer film is easier to form from DLC film than from fluorinated DLC film. The Raman spectra of the transfer films are shown in Figure 4. When Ti6Al4V slides against DLC, the transfer films formed in PBS and BSA solution show typical Raman curves of amorphous carbon, which have a D peak at about $1350 \mathrm{~cm}^{-1}$ and a $G$ peak at about $1580 \mathrm{~cm}^{-1}$ (Figure $4 \mathrm{a}$ ). When Ti6Al4V slides against FDLC, the transfer film formed in PBS has a structure of amorphous carbon, however, the debris generated in BSA solution shows neither D peak nor G peak in the Raman curve (Figure $4 \mathrm{~b}$ ). Compare with the tribofilm from DLC in BSA solution, the debris from FDLC in BSA solution does not have an amorphous carbon structure. It seems that $\mathrm{F}$ element is harmful to the formation of lubricating amorphous carbon. We must emphasize here that we have omitted the result of EDS. The tiny peaks of carbon occurring in the EDS results could be attributed to contaminants or the environment. Much more importantly is that EDS measurement is not accurate for light elements. With limited analyses available, the reliable Raman measurement reported here is justifiable.
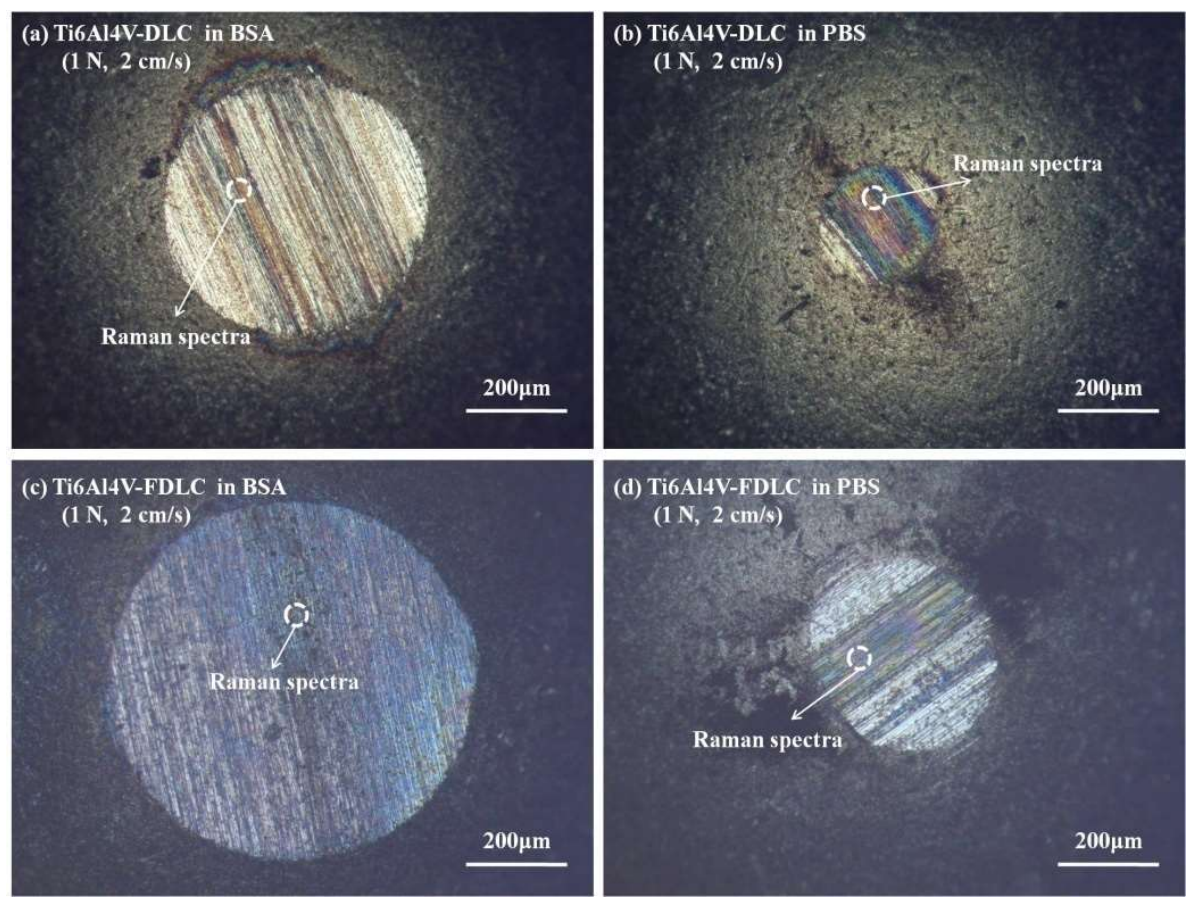

Figure 3. Amplifying images of the wear scars generated by (a) DLC film in BSA solution, (b) DLC film in PBS, (c) FDLC film in BSA solution and (d) FDLC film in PBS under $1 \mathrm{~N}, 2 \mathrm{~cm} / \mathrm{s}$ condition.

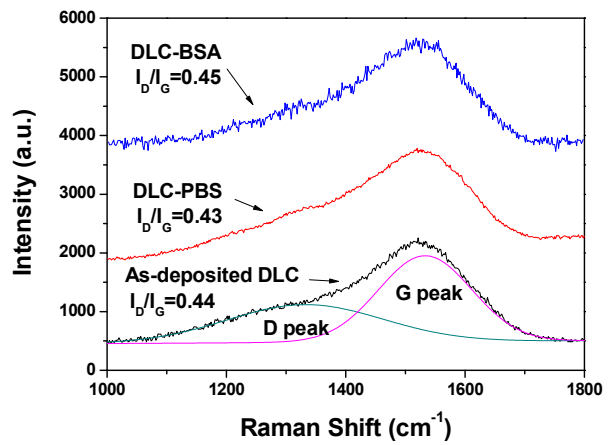

(a)

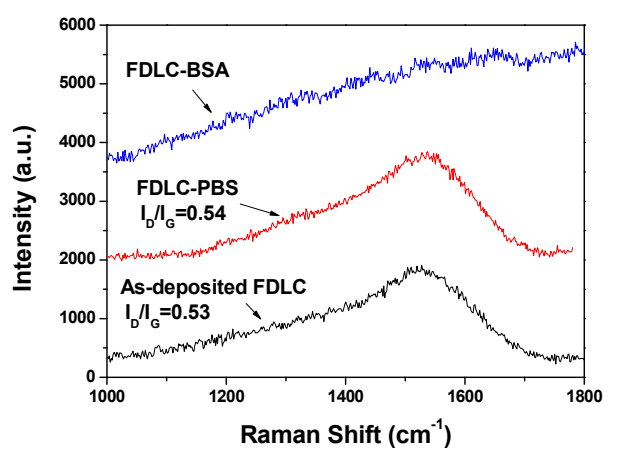

(b)

Figure 4. Raman spectra of tribofilms generated from (a) DLC films and (b) FDLC films under 1 N, $2 \mathrm{~cm} / \mathrm{s}$ condition in PBS and BSA solution. 


\subsubsection{Bulk Wear Rates of Ti6Al4V Counter Balls}

The bulk wear rates of Ti6Al4V balls estimated by Equation (1) are shown in Figure 5. In general, the wear rates of Ti6Al4V balls are lower in PBS (Figure 5b,d) than in BSA solution (Figure 5a,c) probably because the transfer films formed in PBS protected the counter surfaces from further wear. In BSA solution (Figure 5a,c), FDLC caused a higher wear rate of Ti6Al4V than DLC, especially under $0.5 \mathrm{~N}$ and $1 \mathrm{~N}$ load, the reason might be that the worn surface of Ti6Al4V cannot generate a lubricating transfer film with a structure of amorphous carbon. In PBS (Figure 5b,d), FDLC also caused higher wear rate of Ti6Al4V than DLC probably because the transfer film formed from FDLC cannot effectively cover the wear scar.
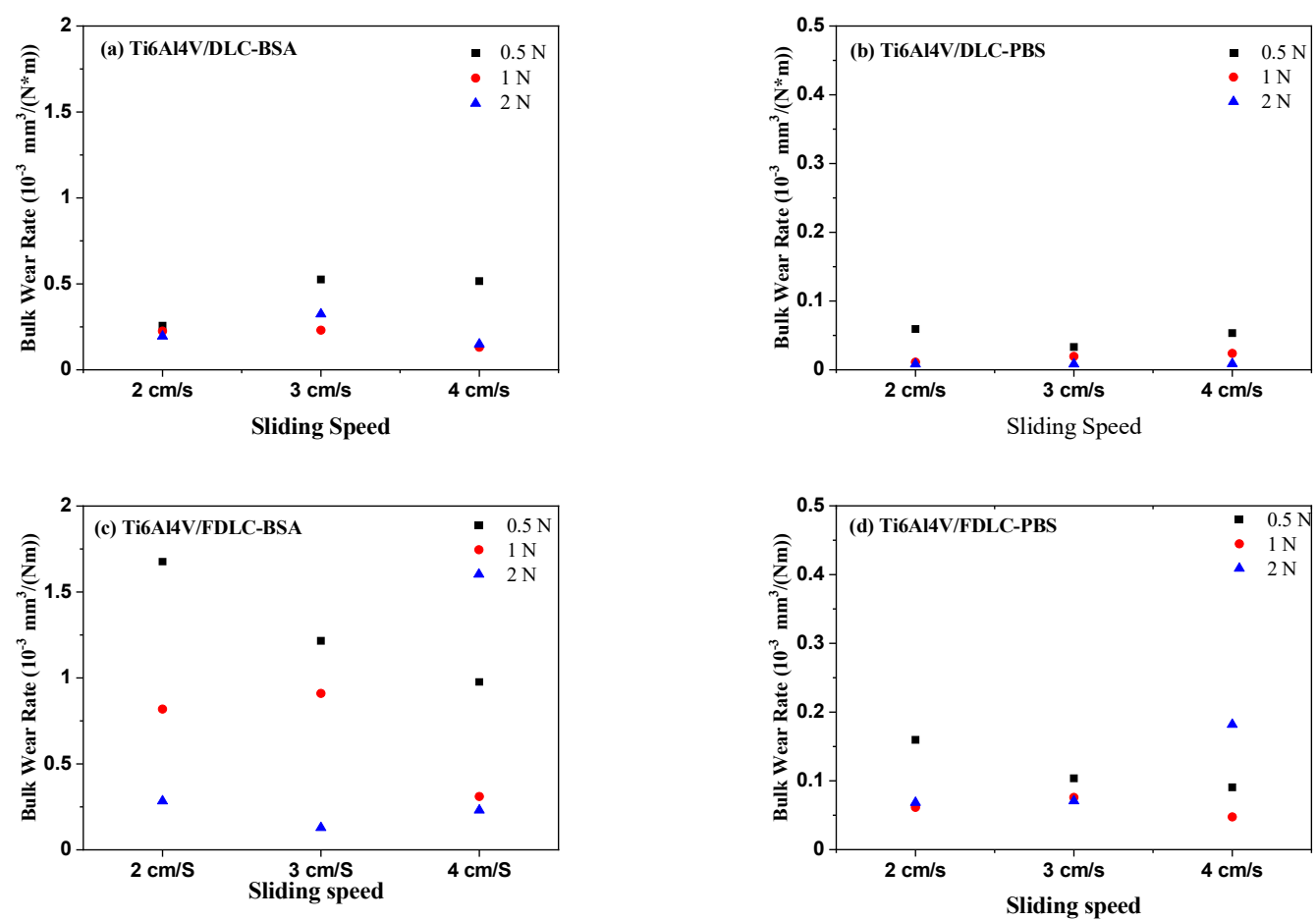

Figure 5. Wear rates of Ti6Al4V balls sliding against (a) DLC films in BSA solution, (b) DLC films in PBS, (c) FDLC films in BSA solution and (d) FDLC films in PBS under different normal loads and sliding speeds.

\section{Discussion}

Transfer film plays an important role in the tribological behavior of DLC film. Flexible transfer film, with a structure of amorphous carbon, can effectively reduce the friction and protect the worn surface [4]. The formation of transfer film can be affected by many factors, especially the lubricating medium and counter materials. In many studies, biomolecules can act as lubricating medium to slow down the wear, especially in metal-metal frictional system [20]. Some reports revealed the protein molecules can transform to lubricating tribofilm under load and friction [21]. However, in DLC-Ti6Al4V friction system, the wear reduction effect of biomolecules is not applicable. In BSA solution, biomolecules may absorb on the friction surfaces (both the Ti6Al4V surface and DLC surface), inhibit the transfer of carbon from DLC to Ti6Al4V counterface, and thus restrain the formation of transfer film. As shown in Figure 2, the transfer films formed in PBS are more sufficient than those formed in BSA solution. So in BSA solutions, without the effective protection of transfer films, DLC and FDLC caused more wear of Ti6Al4V than in PBS.

The F element in FDLC also has influence on the formation of transfer film. On one side the F element can break the continuity of $\mathrm{C}-\mathrm{C}$ bond and induce a low energy surface, this means that the $\mathrm{F}$ containing wear debris is more difficult to adhere on the Ti6Al4V counterface [22,23]. On the other 
hand, FDLC surface was reported to absorb more proteins than undoped DLC surface, which may restrain the transfer of carbon from FDLC to Ti6Al4V surface [19]. As a result, fluorinated DLC film is more difficult to form transfer film on Ti6Al4V counterface than the undoped one in PBS. In BSA solution, fluorinated DLC film cannot produce a transfer film with an amorphous carbon structure on Ti6Al4V counterface due to the combined inhibition effect of absorbed biomolecules and F element.

\section{Conclusions}

The undoped DLC and fluorinated DLC films were deposited on Ti6Al4V substrates. The wear behavior of Ti6Al4V counterface against DLC and fluorinated DLC in PBS and BSA solution was studied. It is shown that the biomolecules cannot act as wear reduction medium in DLC-Ti6Al4V friction system. The absorbed biomolecules can inhibit the formation of transfer film, and thus cause severe wear of the Ti6Al4V counterface. The fluorine element is also adverse to the formation of transfer films, as a result, fluorinated DLC film causes more wear of the Ti6Al4V counterface than undoped DLC film. The fluorinated DLC film might be cautiously selected in the application of DLC-metal friction systems, especially in a lubricating medium with biomolecules.

Author Contributions: Funding acquisition, Z.X. and J.W.; Investigation, T.Z.; Methodology, Y.S.; Project administration, X.H.; Supervision, L.L.; Writing-review \& editing, K.B.C. and S.P. All authors have read and agreed to the published version of the manuscript.

Funding: This work was supported by the Chongqing Technology Innovation and Application Development Project (cstc2019jscx-fxydX0046), the project of Chongqing Science and Technology Bureau (cstc2020jcyj-msxmX0069, cstc2018jcyj-yszxX0003), Scientific and Technological Research Program of Chongqing Municipal Education Commission (KJ1601104, KJQN20181315), the Foundation of Chongqing University of Art and Sciences (R2018SCL29), and the Program for Guangdong Introducing Innovative and Enterpreneurial Teams (2016ZT06G025).

Conflicts of Interest: The authors declare there is no conflict of interest regarding the publication of this paper.

\section{References}

1. Liao, Y.; Pourzal, R.; Wimmer, M.A.; Jacobs, J.J.; Fischer, A.; Marks, L.D. Graphitic Tribological Layers in Metal-on-Metal Hip Replacements. Science 2011, 334, 1687-1690. [CrossRef]

2. Erdemir, A.; Ramirez, G.; Eryilmaz, O.L.; Narayanan, B.; Liao, Y.; Kamath, G.; Sankaranarayanan, S.K. Carbon-based tribofilms from lubricating oils. Nature 2016, 536, 67-71. [CrossRef] [PubMed]

3. Chen, X.C.; Li, J.J. Superlubricity of carbon nanostructures. Carbon 2020, 158, 1-23. [CrossRef]

4. Zhang, T.F.; Jiang, F.; Liao, T.T.; Deng, Q.Y.; Li, S.S.; Wang, Y.; Leng, Y.X. Tribological behavior of diamond like carbon film sliding against $\mathrm{CoCrMo}$ or $\mathrm{Al}_{2} \mathrm{O}_{3}$ in air and water environment. Tribol. Int. 2016, 95, 456-461. [CrossRef]

5. Lafon-Placette, S.; Fontaine, J.; Bouchet, M.I.D.B.; Heau, C. Critical role of a metallic counterpart on the tribochemical wear of ta-C coatings in base oil. Wear 2018, 402-403, 91-99. [CrossRef]

6. Tanaka, A.; Nishibori, T.; Suzuki, M.; Maekawa, K. Characteristics of friction surfaces with DLC films in low and high humidity air. Wear 2004, 257, 297-303. [CrossRef]

7. Guo, P.; Geng, Z.; Lu, Z.; Zhang, G.; Wu, Z. Probing the lubrication mechanism of rough diamond-like carbon films against silicon nitride under water. Tribol. Int. 2018, 128, 248-259. [CrossRef]

8. Suzuki, M.; Tanaka, A.; Ohana, T.; Zhang, W. Frictional behavior of DLC films in a water environment. Diam. Relat. Mater. 2004, 13, 1464-1468. [CrossRef]

9. Hatem, A.; Lin, J.; Wei, R.; Torres, R.D.; Laurindo, C.; Soares, P. Tribocorrosion behavior of DLC-coated Ti-6Al-4V alloy deposited by PIID and PEMS + PIID techniques for biomedical applications. Surf. Coat. Technol. 2017, 332, 223-232. [CrossRef]

10. Escudeiro, A.; Wimmer, M.A.; Polcar, T.; Cavaleiro, A. Tribological behavior of uncoated and DLC-coated $\mathrm{CoCr}$ and Ti-alloys in contact with UHMWPE and PEEK counterbodies. Tribol. Int. 2015, 89, 97-104. [CrossRef]

11. Talha, M.; Ma, Y.; Kumar, P.; Lin, Y.; Singh, A. Role of protein adsorption in the bio corrosion of metallic implants-A review. Colloids Surf. B Biointerfaces 2019, 176, 494-506. [CrossRef] [PubMed] 
12. Wu, B.J.; Deng, Q.Y.; Leng, Y.X.; Wang, C.M.; Huang, N. Characterization of adsorption and lubrication of synovial fluid proteins and HA on DLC joint bearings surface. Surf. Coat. Technol. 2017, 320, 320-332. [CrossRef]

13. Hang, R.; Qi, Y. A study of biotribological behavior of DLC coatings and its influence to human serum albumin. Diam. Relat. Mater. 2010, 19, 62-66. [CrossRef]

14. Guo, F.; Zhou, Z.; Hua, M.; Dong, G. Effect of aqueous solution and load on the formation of DLC transfer film against Co-Cr-Mo for joint prosthesis. J. Mech. Behav. Biomed. Mater. 2015, 49, 12-22. [CrossRef] [PubMed]

15. Wang, J.; Qing, Y.A.; Xiao, L.G.; Wang, Y.G.; Bao, X.F.; Qin, Y.G.; Zhang, J.Y.; Zhang, K. Design of new-type F-FLC artificial joint coatings via fluorine incorporation and fullerene-like structure construction. Surf. Coat. Technol. 2020, 385, 125419. [CrossRef]

16. Imbeni, V.; Martini, C.; Prandstraller, D.; Poli, G.; Trepanier, C.; Duerig, T.W. Preliminary study of micro-scale abrasive wear of a NiTi shape memory alloy. Wear 2003, 254, 1299-1306. [CrossRef]

17. Kim, D.W.; Kim, K.W. Effects of sliding velocity and normal load on friction and wear characteristics of multi-layered diamond-like carbon (DLC) coating prepared by reactive sputtering. Wear 2013, 297, 722-730. [CrossRef]

18. Wu, B.; Zhang, T.; Deng, Q.; Leng, Y.; Huang, N. Effects of Adsorption of Albumin and Gamma-Globulin on the Tribological Performance of a Diamond-Like Carbon Film. J. Wuhan Univ. Technol. Mater. Sci. Ed. 2019, 34, 1103-1108. [CrossRef]

19. Ahmed, M.H.; Byrne, J.A.; McLaughlin, J. Evaluation of glycine adsorption on diamond like carbon (DLC) and fluorinated DLC deposited by plasma-enhanced chemical vapor deposition (PECVD). Surf. Coat. Technol. 2012, 209, 8-14. [CrossRef]

20. Nečas, D.; Vrbka, M.; Gallo, J.; Křupka, I.; Hartl, M. On the Observation of Lubrication Mechanisms within Hip Joint Replacements. Part II: Hard-on-hard Bearing Pairs. J. Mech. Behav. Biomed. Mater. 2019, 89, $249-259$. [CrossRef]

21. Liub, H.C.; Guo, F.; Wong, P.L.; Li, X. Investigation of adsorbed protein and passive films on hydrodynamic lubricated steel slider surface. Tribol. Int. 2017, 109, 133-139.

22. Kanda, K.; Yamada, N.; Yokota, K.; Tagawa, M.; Niibe, M.; Okada, M.; Haruyama, Y.; Matsui, S. Fabrication of fluorine-terminated diamond-like carbon thin film using ahyperthermal atomic fluorine beam. Diam. Relat. Mater. 2011, 20, 703-706. [CrossRef]

23. Liu, Z.; Zheng, S.; Lu, Z.; Pu, J.; Zhang, G. Adhesive transfer at copper/diamond interface and adhesion reduction mechanism with fluorine passivation: A first-principles study. Carbon 2018, 127, 548-556. [CrossRef]

(C) 2020 by the authors. Licensee MDPI, Basel, Switzerland. This article is an open access article distributed under the terms and conditions of the Creative Commons Attribution (CC BY) license (http://creativecommons.org/licenses/by/4.0/). 